\title{
Texture irregularity of pretreatment contrast-enhanced computed tomography as a predictive factor for developing esophageal stricture after chemoradiation therapy for esophageal squamous cell carcinoma
}

Keiichiro Koiwai*, Hironobu Ina, Ayumu Fukazawa, Takesumi Ozawa and Masumi Kadoya

*Correspondence: kkoiwai@shinshu-u.ac.jp

CrossMark

$\leftarrow$ Click for updates

Department of Radiology, Shinshu University, School of Medicine, Matsumoto, Japan.

\begin{abstract}
Background: This study was performed to evaluate whether pre-treatment contrast-enhanced CT (CECT) images have predictive information about esophageal stricture after chemoradiation therapy (CRT) for esophageal squamous cell carcinoma (SCC).

Methods: This retrospective study was performed with institutional review board approval. Nineteen patients with advanced esophageal SCC who underwent CRT at our institution from February 2006 to July 2014 were selected for this study. Eight of the 19 patients (42.1\%) developed esophageal stricture after CRT. In each patient, a three-dimensional data set was created from the pre-treatment CECT images, and the esophageal lesion was delineated as one structure. Volumetric and texture analyses were performed for each structure. The mean and standard deviation (SD) of CT number was examined in texture analyses.

Results: On volumetric analysis, there was no difference in the mean volume of the esophageal lesion between the patients with and without stricture (15.1 vs. $14.7 \mathrm{~mL}$, respectively, $\mathrm{P}=0.9435)$. On texture analyses, there was no difference between in the mean value of mean CT number between the patients with and without stricture (74.8 vs. $74.2 \mathrm{HU}$, respectively, $\mathrm{P}=0.9326)$. On the other hand, the mean value of SD of CT number in the patients with stricture was significantly greater than that in the patients without stricture (24.8 vs. 19.5 $\mathrm{HU}$, respectively, $\mathrm{P}=0.0221)$.

Conclusion: The SD of CT number (i.e., texture irregularity) in esophageal lesions in pre-treatment CECT could be a predictive factor for development of esophageal stricture after CRT for esophageal SCC.
\end{abstract}

Keywords: Chemoradiation therapy, esophageal stricture, texture analysis, predictive factor

\section{Introduction}

Chemoradiation therapy (CRT) is widely accepted as the standard of care for esophageal squamous cell carcinoma (SCC) $[1,2]$. Although advanced esophageal carcinoma is incurable with radiotherapy alone [1], it has been shown to be curable with CRT [3]. Surgery has been recognized as the most effective treatment for esophageal SCC, but the therapeutic effect of CRT is not necessarily inferior to that of surgery [4]. CRT is the only way for patients with inoperable esophageal SCC to survive [5]. On the other hand, CRT is well known for its toxicities [6]. Esophageal stricture is one such toxicity, which usually appears during or just after the course of CRT [7] and reduces the quality of life (QOL) of the patients. However, there have been few studies related to this toxicity. Especially, there have been few studies related to prediction of stricture development [7]. In this study, we analyzed pre-treatment contrast-enhanced CT (CECT) imaging of esophageal SCC and evaluated whether it yielded predictive information about esophageal stricture after CRT.

\section{Materials and methods \\ Patients}

All procedures followed were in accordance with the ethical standards of our institutional review board and with the Hel- 
sinki Declaration of 1964 and later versions. Our institutional review board approved this retrospective study and waived the need for informed consent from the patients.

Candidates were selected for this study from the patient database of our institution according to the following selection criteria: diagnosis of advanced esophageal SCC, completion of planned CRT between February 2006 and July 2014, acquisition of analyzable CECT images in equilibrium phase before treatment, and complete response of the esophageal lesion to therapy. "Advanced" was defined as the presence of T3 or T4 in staging according to the 7th edition of the Union for International Cancer Control (UICC) tumor, node, metastasis (TNM) staging system [8]. The response of the esophageal lesion was confirmed by both endoscopy and CT scan several weeks after completion of therapy. We judged that the lesion responded completely when the endoscopy revealed disappearance of the intraluminal tumor and the CT scan revealed definitive shrinkage of the whole tumor. During the above period, 58 patients with advanced esophageal SCC were treated with CRT at our institution. Among these patients, 19 patients met all of the selection criteria above and were selected for this study. The residual 39 patients were excluded because they didn't meet at least one of the criteria. Eight of the selected patients (42.1\%) developed esophageal stricture, which was confirmed endoscopically within 3 months after completion of therapy.

\section{Analysis}

All patients underwent pretreatment CECT scan of the entire thorax for diagnostic purposes. All CT studies were performed with multi-detector row CT scanners at our institution. lodinated contrast agent $(100 \mathrm{~mL}$ of $300 \mathrm{mg} / \mathrm{mL}$ ) was injected at $3 \mathrm{~mL} / \mathrm{s}$ in each CT study. The CECT images in the equilibrium phase were chosen for analysis. They were reconstructed from the raw data acquired essentially $90 \mathrm{~s}$ after injection of the contrast agent, with a section thickness of $2.5 \mathrm{~mm}$.

Both volumetric and texture analyses of the images were performed. This required creation of analyzable three-dimensional data sets from the images. A radiation treatment planning system (RTPS) fulfilled this requirement. The images were transferred to the RTPS (Eclipse version 11.0; Varian Medical Systems, Palo Alto, CA), and the RTPS converted the images into three-dimensional voxel data sets. The side of the voxel was set at $2.5 \mathrm{~mm}$. The data sets were analyzed on the same RTPS, and volumetric and the texture analyses were performed.

At the beginning of these analyses, the esophageal lesion was contoured on the RTPS. The entire lesion was manually delineated as one structure in contouring. Intraluminal air was carefully deleted from the structure to reduce bias. A researcher (KK) contoured lesions of all patients. An example is shown in Figure 1.

Parameters for analyses were acquired from the results of the calculation performed automatically by the RTPS on each
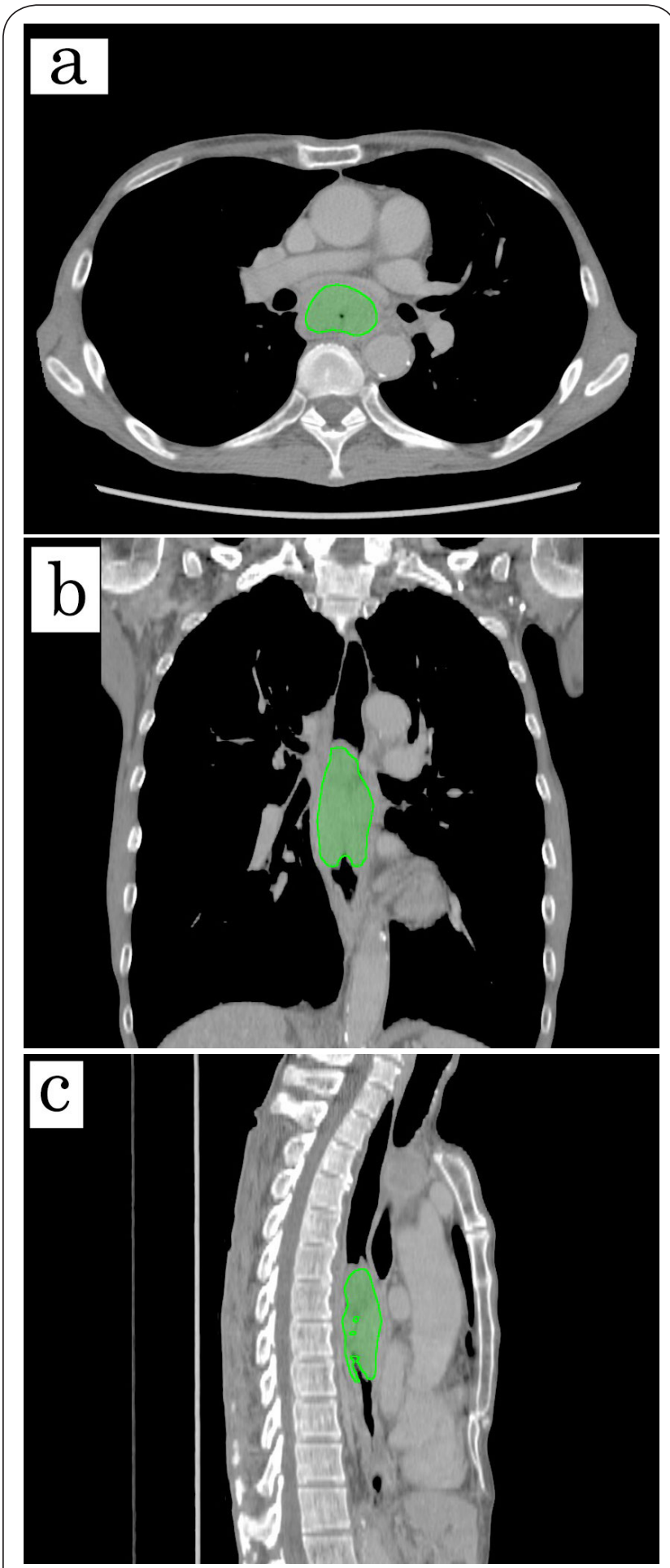

Figure 1. An example of an esophageal lesion contoured on the radiation treatment planning system.
a) Axial image.
b) Coronal image.
c) Sagittal image.

structure. The RTPS calculated the parameters as follows: the volume of the structure $(\mathrm{mL})$, the mean value and standard 
Koiwai et al. Medical Imaging and Radiology 2018,

deviation (SD) of the CT number of the structure (Hounsfield units, HU). Volumetric analysis was performed with the volume of the structure and texture analysis with the mean value and SD of the CT number of the structure. The relationships between these parameters and the occurrence of esophageal stricture after CRT for esophageal SCC were evaluated.

The parameters were compared with the paired $t$ test. The level of significance was set at 0.05 . Receiver operator characteristic (ROC) curves were plotted to evaluate the capability of the parameters to predict the development of stricture. Areas under the curve (AUC) and cutoff values were also calculated. These statistical analyses were performed with the statistical software JMP version 9.0.0 (SAS Institute Inc., Cary, NC).

\section{Results}

Table 1 shows the characteristics of the patients with and without stricture. There were few differences between the two groups. Patients in both groups received $50-60$ Gy of radiation in conventional fractionation and platinum-based chemotherapy.

On volumetric analysis, no differences were found in mean volume of the esophageal lesion between patients with and without esophageal stricture (15.1 vs. $14.7 \mathrm{~mL}$, respectively, $P=0.9435)$. On texture analysis, no differences were found in mean CECT number between patients with and without stricture ( 74.8 vs. $74.2 \mathrm{HU}$, respectively, $P=0.9326)$. On the other hand, the mean value of SD of the CECT number was significantly higher in patients with than without stricture

Table 1. Characteristics of patients with and without stricture.

\begin{tabular}{|c|c|c|}
\hline & Patients with stricture & Patients without stricture \\
\hline Age (yrs.) & 59 - 76 (median: 65) & $48-77$ (median: 66) \\
\hline \multicolumn{3}{|l|}{ Gender } \\
\hline Male & 8 & 9 \\
\hline Female & 0 & 2 \\
\hline \multicolumn{3}{|l|}{ Performance status ${ }^{*}$} \\
\hline 0 & 4 & 7 \\
\hline 1 & 4 & 4 \\
\hline \multicolumn{3}{|l|}{ Tumor location } \\
\hline Cervical & 2 & 2 \\
\hline Thoracic & 6 & 9 \\
\hline \multicolumn{3}{|l|}{ T stage } \\
\hline T3 & 5 & 5 \\
\hline $\mathrm{T} 4$ & 3 & 6 \\
\hline Radiation dose (Gy) & $50-63$ (median: 60) & $50.4-63$ (median: 60) \\
\hline \multicolumn{3}{|l|}{ Chemotherapy } \\
\hline Cisplatin + 5-FU & 5 & 7 \\
\hline Nedaplatin + 5-FU & 3 & 4 \\
\hline
\end{tabular}

${ }^{\star}$ Performance status according to the Eastern Cooperative Oncology Group.
(24.8 vs. $19.5 \mathrm{HU}$, respectively, $\mathrm{P}=0.0221$ ). ROC analysis of SD of the CECT number as a predictive factor for stricture was performed. The AUC was 0.81 , and its cutoff value was $23.3 \mathrm{HU}$. The ROC curve of SD of the CECT number is shown in Figure 2.

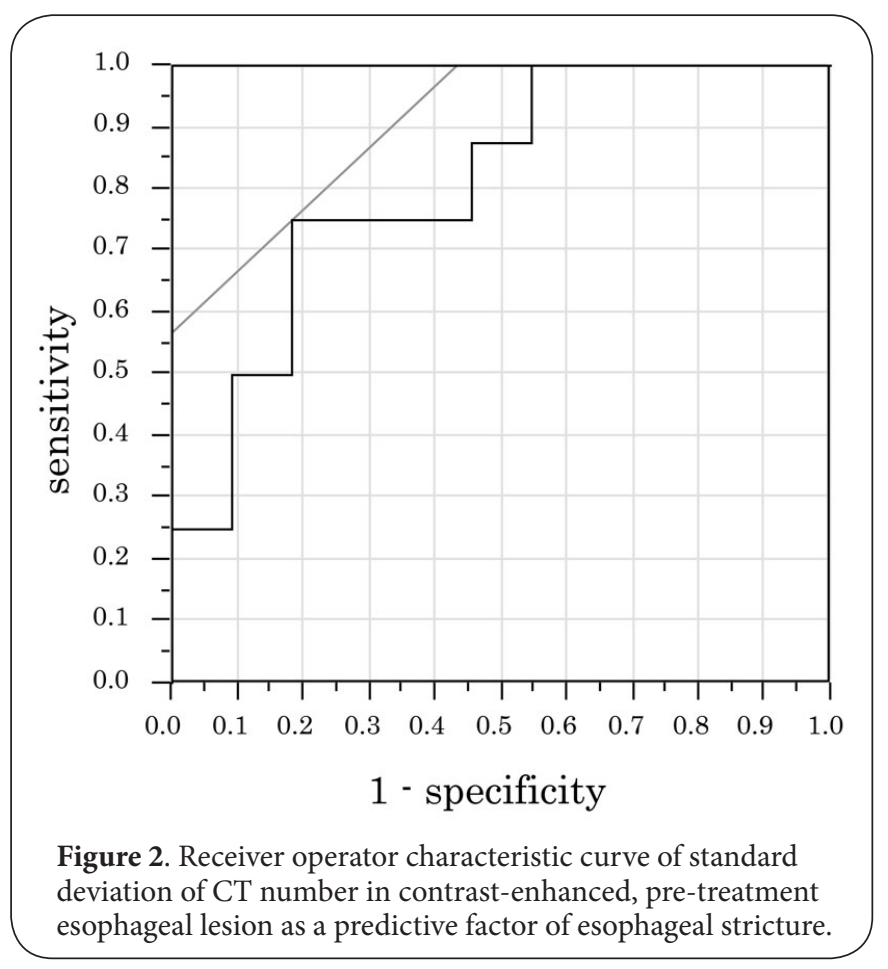

\section{Discussion}

There have been a number of recent studies related to extracting quantitative information from medical images [9]. In this approach, several predictive biomarkers for esophageal carcinoma have been detected. Imanishi et al. reported that early response to chemoradiation therapy of advanced esophageal SCC could be predicted by diffusion-weighted magnetic resonance imaging [10]. Hayano et al. reported similar results with perfusion CT imaging [11]. However, there have been few studies regarding factors derived from medical images to predict esophageal stricture after CRT for esophageal SCC. Atsumi et al. reported that morphological features in medical images could be predictive factors for stricture [12], but there have been no previous reports regarding predictive factors in terms of the texture of CT images. To our knowledge, our report is the first one that the texture of $\mathrm{CT}$ images has predictive information about esophageal stricture after CRT for esophageal SCC.

There is mounting evidence related to texture analysis on medical images. Several studies have shown that some factors in texture analysis could be used as biomarkers in some cancers, including esophageal cancer [13,14]. Yip et al. reported intriguing results of texture analysis on CECT images of esophageal 
carcinoma treated with definitive CRT [15]. They showed that heterogeneity of CECT images was significantly associated with overall survival time of patients with the disease. The results of our study may be related to their observations, because the occurrence of esophageal stricture may affect the prognosis of the patients. Our findings may add to the potential of texture analysis on CECT images of esophageal carcinoma.

One of the distinctive features of our study was the use of RTPS. Recent RTPS have been equipped with highly sophisticated tools for delineation. Structures as regions of interest can be delineated with these tools reproducibly. Moreover, almost all commercially available RTPS have the ability to calculate the mean value and SD of CT numbers in regions of interest in three dimensions [16]. Hence, users of standard RTPS can perform simple three-dimensional texture analysis on their own system, as shown in this article. There are many other ways of texture analysis utilized for esophageal cancer $[13,14]$. There might be more suitable ways of analysis than ours. Unfortunately, our RTPS can only perform the simple analysis. Evaluation by other ways of analysis is beyond our current capability. We hope this will be performed in the future studies.

The rationale for the association of the SD of the CT number in the pre-treatment CECT with esophageal stricture after CRT is difficult to clarify, but a hypothesis could be described.

High SD of CECT number in a tumor means that the tumor is irregularly enhanced with the contrast agent. This irregularity may represent the immaturity of the microcirculation in the tumor [17]. Tumors with immature microcirculation may be susceptible to hypoxic changes, which are known to induce fibrosis [18]. Hypoxia-induced fibrosis may be augmented by chemoradiation and result in esophageal stricture. Thus, the $\mathrm{SD}$ of the CT number in pre-treatment CECT may represent the susceptibility to hypoxia-induced fibrosis in the esophageal region after CRT for esophageal SCC.

Prediction of esophageal stricture before treatment may aid in maintaining the patient's QOL after CCRT. Severe esophageal stricture causes dysphagia and aspiration pneumonia, and is sometimes a threat to patients' lives [12]. Identification of high-risk patients through prediction of stricture after CCRT may facilitate focused follow-up and appropriate interventions to save their lives.

Our study had several limitations. First, the sample size was small. Larger sample size is needed in order to perform more rigorous analysis. In addition, it is impossible for us to perform subset analysis, e.g. dividing the patients according to their tumor locations. Second, the level of esophageal stricture was not evaluated quantitatively. Third, different CT scanners were used in the cohort included in our study. There was some possibility that this might have affect the texture of the images. Further studies are warranted for validation of the results presented here.

\section{Conclusion}

The SD of the CT number (i.e., the irregularity of the texture) in pre-treatment CECT was significantly associated with the development of esophageal stricture after CRT for esophageal SCC and could be a predictor of toxicity.

\section{Competing interests}

The authors declare that they have no competing interests.

Authors' contributions

\begin{tabular}{|l|c|c|c|c|c|}
\hline Authors' contributions & KK & HI & AF & TO & MK \\
\hline Research concept and design & $\checkmark$ & -- & $\checkmark$ & -- & -- \\
\hline Collection and/or assembly of data & $\checkmark$ & $\checkmark$ & -- & $\checkmark$ & -- \\
\hline Data analysis and interpretation & $\checkmark$ & -- & -- & -- & -- \\
\hline Writing the article & $\checkmark$ & -- & -- & -- & $\checkmark$ \\
\hline Critical revision of the article & $\checkmark$ & -- & -- & -- & -- \\
\hline Final approval of article & $\checkmark$ & $\checkmark$ & $\checkmark$ & $\checkmark$ & $\checkmark$ \\
\hline Statistical analysis & $\checkmark$ & -- & -- & -- & -- \\
\hline
\end{tabular}

Acknowledgments

The authors are grateful to Mrs. I. Koiwai and

Mrs. Y. Ogawa for their support.

\section{Publication history}

Senior Editor: Domenico Rubello, Santa Maria della Misericordia Hospital, Italy.

Received: 07-May-2018 Final Revised: 29-May-2018

Accepted: 01-Jun-2018 Published: 21-Jun-2018

\section{References}

1. Cooper JS, Guo MD, Herskovic A, Macdonald JS, Martenson JA, Jr., Al-Sarraf M, Byhardt R, Russell AH, Beitler JJ, Spencer S, Asbell SO, Graham MV and Leichman LL. Chemoradiotherapy of locally advanced esophageal cancer: long-term follow-up of a prospective randomized trial (RTOG 85-01). Radiation Therapy Oncology Group. JAMA. 1999; 281:1623-7. | Article | PubMed

2. Kachnic LA, Winter K, Wasserman T, Kelsen D, Ginsberg R, Pisansky TM, Martenson J, Komaki R, Okawara G, Rosenthal SA, Willett CG and Minsky BD. Longitudinal Quality-of-Life Analysis of RTOG 94-05 (Int 0123):A Phase III Trial of Definitive Chemoradiotherapy for Esophageal Cancer. Gastrointest Cancer Res. 2011; 4:45-52. | PubMed Abstract | PubMed FullText

3. Kato K, Muro K, Minashi K, Ohtsu A, Ishikura S, Boku N, Takiuchi H, Komatsu Y, Miyata Y and Fukuda H. Phase II study of chemoradiotherapy with 5-fluorouracil and cisplatin for Stage II-III esophageal squamous cell carcinoma: JCOG trial (JCOG 9906). Int J Radiat Oncol Biol Phys. 2011; 81:684-90. | Article | PubMed

4. Bedenne L, Michel P, Bouche O, Milan C, Mariette C, Conroy T, Pezet D, Roullet B, Seitz JF, Herr JP, Paillot B, Arveux P, Bonnetain F and Binquet C. Chemoradiation followed by surgery compared with chemoradiation alone in squamous cancer of the esophagus: FFCD 9102. J Clin Oncol. 2007; 25:1160-8. | Article | PubMed

5. Ishida $\mathrm{K}$, Ando $\mathrm{N}$, Yamamoto $\mathrm{S}$, Ide H and Shinoda M. Phase II study of cisplatin and 5-fluorouracil with concurrent radiotherapy in advanced squamous cell carcinoma of the esophagus: a Japan Esophageal Oncology Group (JEOG)/Japan Clinical Oncology Group trial (JCOG9516). Jpn J Clin Oncol. 2004; 34:615-9. | Article | PubMed

6. Ishikura S, Nihei K, Ohtsu A, Boku N, Hironaka S, Mera K, Muto M, Ogino $T$ and Yoshida $S$. Long-term toxicity after definitive chemoradiotherapy for squamous cell carcinoma of the thoracic esophagus. J Clin Oncol. 2003; 21:2697-702. | Article | PubMed

7. Atsumi K, Shioyama $Y$, Nakamura K, Nomoto $S$, Ohga S, Yoshitake T, Nonoshita T, Ueda M, Hirata $\mathrm{H}$ and Honda $\mathrm{H}$. Predictive factors of 
Koiwai et al. Medical Imaging and Radiology 2018,

esophageal stenosis associated with tumor regression in radiation therapy for locally advanced esophageal cancer. J Radiat Res. 2010; 51:9-14. | Article | PubMed

8. Sobin L, Gospodarowicz M and Wittekind C. Oesophagus including Oesophagogastric Junction. In 7th ed., TNM classification of malignant tumors 2010; 66-72.

9. Lambin P, Rios-Velazquez E, Leijenaar R, Carvalho S, van Stiphout RG, Granton P, Zegers CM, Gillies R, Boellard R, Dekker A and Aerts HJ. Radiomics: extracting more information from medical images using advanced feature analysis. Eur J Cancer. 2012; 48:441-6. | Article | PubMed Abstract I PubMed FullText

10. Imanishi S, Shuto K, Aoyagi T, Kono T, Saito H and Matsubara H. Diffusionweighted magnetic resonance imaging for predicting and detecting the early response to chemoradiotherapy of advanced esophageal squamous cell carcinoma. Dig Surg. 2013; 30:240-8. | Article | PubMed

11. Hayano K, Okazumi S, Shuto K, Matsubara H, Shimada H, Nabeya Y, Kazama T, Yanagawa $\mathrm{N}$ and Ochiai T. Perfusion $\mathrm{CT}$ can predict the response to chemoradiation therapy and survival in esophageal squamous cell carcinoma: initial clinical results. Oncol Rep. 2007; 18:901-8. | Article | PubMed

12. Atsumi $K$, Shioyama $Y$, Arimura $H$, Terashima $K$, Matsuki T, Ohga $S$, Yoshitake T, Nonoshita T, Tsurumaru D, Ohnishi K, Asai K, Matsumoto K, Nakamura $\mathrm{K}$ and Honda H. Esophageal stenosis associated with tumor regression in radiotherapy for esophageal cancer: frequency and prediction. Int J Radiat Oncol Biol Phys. 2012; 82:1973-80. | Article | PubMed

13. Tixier F, Le Rest CC, Hatt M, Albarghach N, Pradier O, Metges JP, Corcos $L$ and Visvikis $D$. Intratumor heterogeneity characterized by textural features on baseline 18F-FDG PET images predicts response to concomitant radiochemotherapy in esophageal cancer. J Nucl Med. 2011; 52:369-78. | Article | PubMed Abstract | PubMed FullText

14. Mattonen SA, Palma DA, Haasbeek CJ, Senan S and Ward AD. Early prediction of tumor recurrence based on $\mathrm{CT}$ texture changes after stereotactic ablative radiotherapy (SABR) for lung cancer. Med Phys. 2014; 41:033502. | Article | PubMed

15. Yip C, Landau D, Kozarski R, Ganeshan B, Thomas R, Michaelidou A and Goh V. Primary esophageal cancer: heterogeneity as potential prognostic biomarker in patients treated with definitive chemotherapy and radiation therapy. Radiology. 2014; 270:141-8. | Article | PubMed

16. Mutic S, Palta JR, Butker EK, Das IJ, Huq MS, Loo LN, Salter BJ, McCollough $\mathrm{CH}$ and Van Dyk J. Quality assurance for computedtomography simulators and the computed-tomography-simulation process: report of the AAPM Radiation Therapy Committee Task Group No. 66. Med Phys. 2003; 30:2762-92. | Article | PubMed

17. Cuenod CA, Fournier L, Balvay D and Guinebretiere JM. Tumor angiogenesis: pathophysiology and implications for contrast-enhanced MRI and CT assessment. Abdom Imaging. 2006; 31:188-93. | Article | PubMed

18. Choi SH, Hong ZY, Nam JK, Lee HJ, Jang J, Yoo RJ, Lee YJ, Lee CY, Kim KH, Park S, Ji YH, Lee YS and Cho J. A Hypoxia-Induced Vascular Endothelialto-Mesenchymal Transition in Development of Radiation-Induced Pulmonary Fibrosis. Clin Cancer Res. 2015; 21:3716-26. | Article | PubMed

\section{Citation:}

Koiwai K, Ina H, Fukazawa A, Ozawa T and Kadoya M. Texture irregularity of pretreatment contrast-enhanced computed tomography as a predictive factor for developing esophageal stricture after chemoradiation therapy for esophageal squamous cell carcinoma. Med Imaging Radiol. 2018; 6:1.

http://dx.doi.org/10.7243/2054-1945-6-1 